\title{
Management Business Model and Data Analysis
}

\author{
Sri Pentapati \\ ECE Department, Gitam University \\ harshavardhanpentapati@gmail.com
}

\begin{abstract}
This paper investigates the role of data management, data analytics, and business intelligence in process management. The findings suggest how the terms are interrelated. This paper elaborates in detail about the methodologies used in the past, tools, and strategies adopted in the present and the future scope of business process management. It also studies the impact of business analytics and business intelligence on supply chain management. The study of the Lean and Six Sigma approach towards process improvement is also a part of the paper.
\end{abstract}

Keywords: Data management, Analytics, Business Intelligence, Business Process Management, Balanced Scorecard, Business Process, Architecture, Six Sigma, Lean.

\section{Introduction}

Technology is improving day by day. It has become challenging for organizations to manage data and keep themselves up to date with the latest technology. It has also led to a competitive situation in the market. In order to stay in the market, industries need to work on the process management and improvement strategy. Information technology has opened gates for organizations to automate, improve and change the business process. Since the current focus is on activities and processes, this demands Business Process Management Activities to optimize the activities and integrate BPM with IT. This paper discusses the definitions, tools, and techniques that significantly impact business functions and profit margins.

\section{Different Approach towards Process Management and Process Improvement}

\subsection{Data Quality}

The uniformity and comprehensiveness of the data are referred to as Data Quality [33]. It has been evaluated that many BI projects face failure due to a lack of quality data, and reports suggest that poor data quality has cost more than $\$ 600$ billion a year in U.S. businesses. (Giovinazzo, 2009) Deficit of data handling activities, poor data management strategies, and faults in the moving process from one system to another lead to poor data reliability. It is challenging for organizations to satisfy customer requirements if the information is not analysed accurately or consistently. BI serves the need for accurate information to enhance organization performance (Eckerson, 2004). Also, the source of data affects data quality. BI applications such as OLAP, data mart can manage it in the case of internal sources of data.

Nevertheless, managing data from external sources is a typical task as it is updated in the data warehouse. Good quality data is a vital factor for the success of BI (Haddad, 2009).

\subsection{Data Analytics}

The uniformity and comprehensiveness of the data are referred to as Data analytics, Big Data analytics, or Business Data analytics are interchangeable terms. (Figure 2.2).

(Russom, 2011)

(Pentapati, 2021)

Big data analytics comprises of big data. Big Data can be defined by its three attributes: Volume, Velocity and Variety. Each of the Vs has different outcomes which is shown in the figure 1.

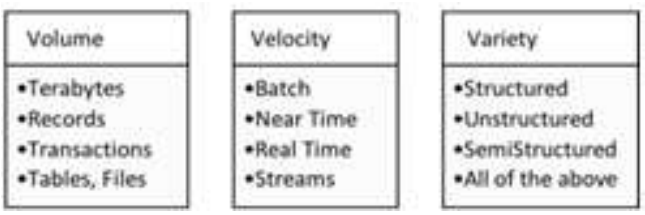

Figure 1: $3 \mathrm{Vs}$ of Big Data

(Russom, 2011)

Reasons for using the term big data and analytics together

- The statistical samples provided by Big Data are vast, which helps to upgrade analytic tool results.

- Progress and development of analytic tools and databases makes them able to work on big data.

- Tools required to handle big data are affordable even by small-sized companies.

- Handling big data analytics provides good learning.

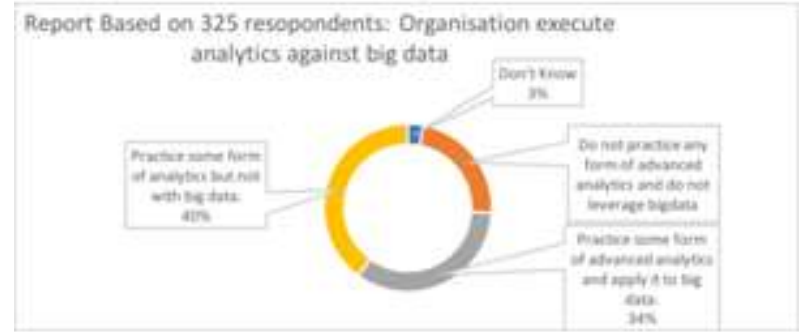

Figure 2 (Picture 3)

Benefits of Big Data Customers get benefits in terms of social influencer marketing, consumer behaviour, market opportunities as well as customer-base segmentation. The figure shows that big data also serves benefit for business intelligence. Some of the terms used are business insights, 
business change, planning, and forecasting. Big data analytics lead in a way to automate decisions in real-time business processes such as fraud detection, risk quantification. The other section in the figure depicts responses like loyalty, optimization, performance in the form of cost and quality.

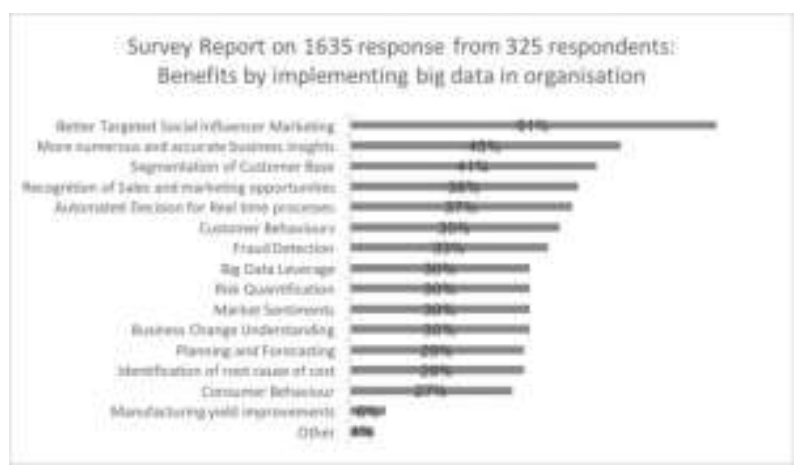

Figure 3 (Picture 4)

Supply Chain Management Activities (SCM) activities emphasize improving the process by proper utilization of all the information, which helps to boost the information processing capacity (H. Zhou, 2007). Thus, SC efficiency has information processing and knowledge development process as its predecessor (G.T.M. Hult, 2011). BA is very vital in SCM as an improvement can significantly improve the performance of a single company and entire SC (Cagliano, 2006; Stadtler, 2008; Trkman, 2007).

\subsection{Business Analytics as a tool to increase information processing Capabilities}

People decide and work depending on the industries and supply chain performance differences (Carlsson, 2008). Therefore, it is the responsibility of IT-qualified business analysts to support the decision-making process. BA plays a pivotal role as in this new era, IT is a critical part of business process and also supply chain management (Valente, 2007; $\mathrm{Yu}, 2010)$.

\subsection{Impact of Business Analytics on performance}

It is a difficult job to observe and upgrade the SC execution activities, and also many of the management processes are involved in it, such as identity, define, plan, monitor, communicate, report. To manage SC relying on old approaches and techniques will never work. It concludes that data analytics is the heart of all business processes and activities(S. Cadez, 2008). The utilization of BA promotes efficiency within the enterprise, and this is possible by using analytical strategies for decisionmaking, leading to deduction in costs of operations, and future trends in the market can be forecasted in a precise way. (Hedgebeth, 2007) The Supply Chain Operations Reference (SCOR) model covers four core supply chain activities- Plan, Source, Make, Deliver, Return (added later) (J. Cai, 2009). How analytics cover these areas is mentioned here.

Plan: To predict market trends by analyzing and comparing organizations data (B. Azvine, 2005);

- Source: the utilization of an agent-based acquisition system for the selection of suppliers, price bargain and evaluating distributors improvement processes( $\mathrm{P}$. Trkman)

- Make: Each of the inventory products must be appropriately manufactured in terms of time, production belt, and batch (Ranjan, 2008)

- Deliver: BA has a significant impact on the delivery process. Many BA applications find their way to logistics management to make products readily available in the market (Reyes, 2005).

BA can be worth it for the companies if the industries are ready for the change in the business process followed; implementation of change management. These all things leverage information for process management and process improvement.

\subsection{Business Intelligence}

Business Intelligence concerns how to capture, retrieve, comprehend, study and convert raw data into applicable information for business process improvement. (Azvine, 2005) According to Gartner, BI is an analytic approach that converts data, i.e., internal and external for the organization, into information that makes it more competitive (Weber and Schffer, 1999; Grothe and Gentsch, 2000). Also, BI holds various information systems notions such as Online Analytical Processing (OLAP), Data Mining, Querying \& Reporting, which supports goal-driven data analysis from the cantered pool. (Chamoni and Gluchowski, 2004)

BI Systems Business Value, A large set of business information, is managed by Enterprise Resource Planning (ERP), and the analytical abilities are provided by the BI systems. To upgrade business process performance, it is a must that the organization possesses decision-making potentials, and BI supports this as it is used as a tool for OLAP, dashboards, queries, and reporting. Data warehouses, data marts, and Extract Transform \& Load ETL tools are the IT infrastructures for BI systems, making them practical to use and deploy.

For an organization to adopt a business environment that gets change at a fast pace requires much effort, and because of the benefits provided by the BI, it acts as a crucial element to upgrade the agility of the organization. BI can be studied from an organizational as well as a technological view. BI is utilized in the organization, such as for sharing roles and risks, is a part of organizational views of BI, whereas a technological perspective focuses on technology and data trends. (J.W. Ross, 1996) Companies performance entirely depends on the way it uses the functions provided by the BI systems.

The difference between previous types of Decision Support System (DSS) and BI BI is an organized combination, aggregation, and management of ordered and unordered data in real-time, leading to new types of fact-based decisions systems (Power, 2003). The current BI systems allow organizations to work on large sets of data with increased processing capabilities, thereby creating options for learning and knowledge findings. Data interrogation and information delivery serve benefits for the BI systems at present. 


\section{Real-time Business Analytics: Combination of Business} Intelligence and Enterprise Application Integration Companies are trying to reduce the time required to respond to business events to increase competition in the market. If the response is made in real-time, i.e., without any delay in taking the inputs and sending the acknowledgment, it is possible to achieve the ideal state. The time to acknowledge the data can be reduced if data gets integrated into real-time, and Enterprise Application Integration (EAI) is a solution. EAI covers small sets of data and information. For extensive data, BI can be utilized. Since the data warehouse is not updated regularly, the BI cannot function on real-time data(Bruckner and Schiefer, 2002). The companies are now focused on real-time decision-making, and for this, they are trying to provide real-time analytics that is the combination of BI and EAI. EAI is used for updating the data in the data warehouse (Bruckner and Schiefer, 2002). BI provides a tool for analytics and reporting.

\section{Balanced Scorecard}

\subsection{From theory to practice}

A balanced scorecard is an approach that helps the organization to form a strategy and then perform it to action. The Balanced Scorecard originated by Robert Kaplan and David Norton (1992)(Kaplan, 1992). Kaplan and Norton used the strategy of the Balanced Scorecard to satisfy stakeholder needs. The BSC was developed as a measurement system and was systemize by four different aspects:

- The financial aspects: the role played by an organization for the stakeholder for financial success. - The customer aspect: to assess service provided to customers.

- The internal aspect: focus on shareholders and customers to improve the respective business processes.

The learning aspect: learnability from previous projects and incorporating the benefits in the current project.

The Business Scorecard concerns achieving the following management activities: 1) Simplify, convert and act on the vision and approach, 2) Transfer and associate the target and goals.3) Develop a plan, set goals and techniques, and deploy, and 4) promote feedback and learning.

Kaplan and Norton have set a nine-step process to create and implement a business scorecard in an organization.

1) Assess all the departments of an organization

2) Find the suitable strategy that fits.

3) Define Views and approaches.

4) Create a strategy map.

5) Manage performance metrics.

6) Filter the strategic initiatives and then arrange according to the priority.

7) Regulation and Report.

8) Execute the balanced scorecard approach all over the organization.

9) Gather data, assess, and review.

The Balanced Scorecard laid the foundation for a new management technique. The scorecard does not only count on short-term financial services but performs specific additional tasks (Samir Ghosh, 2006)

1) Transform strategy and plan to action.

2) Management of critical assets such as creativity and innovation, the loyalty of customers.

3) Increase cross-functionality inside the organization without changing the structure.

4) Measures every fact from ordinary to critical.

5) It helps to manage the system on a day-to-day basis.

\section{Six Sigma \& Lean}

\section{Incremental Improvement Approach}

Lean and Six Sigma are both the methods carried out for process improvement. However, what makes them different is that SIX SIGMA presents an organizational structure to sustain continuous process improvement, thereby making the employees aware of it. In contrast, LEAN concentrates on the activities flow improvement and reduce process cost by reducing different types of waste. Lean and Six-Sigma are explained in detail in this section.

\subsection{Six Sigma}

Six Sigma got its root from Motorola Inc in the USA in 1985. (Kevin Linderman) This was when Japanese companies were rivals in electronic industries, and US companies needed a significant change in quality improvement. (Harry and Schroeder, 2000) From the statistical perspective, Motorola used Six Sigma to show its quality goal of having $99.9997 \%$ as a success rate, where Sigma represents variation about the process average. (Antony, 2002) From the business perspective, six Sigma is a business approach to raise business profits to improve operations effectiveness and efficiency for customer satisfaction. (Antony) The critical step involved in Six Sigma is to define defects in terms of critical to quality parameters after determining the customer requirements. (Young Hoon Kwak)

Understanding Six Sigma Six Sigma is a logical, datadriven strategy that uses the DMAIC process, i.e., define, measure, analysis, improve and control, and employing the DFSS acronym of design for the six sigma method. (Young Hoon Kwak)

SixSigma $=\mathrm{CQI}($ orTQM $)+\mathrm{SCF}+\mathrm{ADAT}+\mathrm{FR}+\mathrm{PM}($ Anbari, 2002)

Where,

CQI $=$ Continuous Quality Improvement

TQM = Total Quality Management

$\mathrm{SCF}=$ Stronger Customer Focus

ADAT $=$ Additional Data Analysis Tools

FR $\quad=$ Financial Results

PM = Project Management

DMAIC It involves the elimination of useless steps, and achieving continuous improvement by using the latest technology and measurements

DFSS is the method to design products and processes by using the tools and training, techniques, and measurement to meet customer demand and produce services that meet Six Sigma quality levels. 
Benefits of Six Sigma Adopting Six Sigma reduced defect levels by significant numbers in the manufacturing sector. It was reported that in GE, turnaround time at repair shops was reduced by $62 \%$. (Young Hoon Kwak). In financial institutions, six Sigma improved the accuracy of reporting and which cash was allocated (Doran, 2003). Healthcare is a sector where mistakes tolerance is zero. Six Sigma projects in healthcare include inventory reduction of surgical equipment and improving compensation claims and timings (Lazarus, 2001). Six Sigma focuses on reducing cost, improving and speeding up research and development processes in the $\mathrm{R} \& \mathrm{R} \& \mathrm{D}$ Sector.

Four Key factors for successful implementation of Six Sigma

- Organisation commitment in terms of cost, time, resources, and tasks performed.

- Selection, Documentation, Evaluation, and learning mechanism of the Project.

- Adapt and Encouragement of Cultural Change.

- Learning the latest tools and techniques. (Young Hoon Kwak)

Issues related to Six Sigma It is believed that SixSigma is a modified version of traditional methods for quality improvement (Catherwood, 2002). Also, SixSigma must concern the manufacturing level and focus on the design level (McClusky, 2000). Organizations likely fail if they do not understand the real problem lies in the implementation of six sigma or when it comes to change management. (Young Hoon Kwak). Proper training is a must for adopting the six sigma approach..

\subsection{Lean}

Lean has invented at the Toyota production, and the literature started with the publication of Taichi Ohno's book Toyota Production System in 1978. Lean is a process improvement approach that manages and improves corporate efforts. Many people prefer to use the term TPS or Toyota Way for lean. There are two pillars for TPS: Continuous Improvement and Respect for people, which further use the five basic approaches: Challenge, Kaizen, Respect, Teamwork, GenchiGenbutau. There are two improvement methods of Kaizen in LEAN:

Flow Kaizen: enterprise-level and focus to improve high value stream flow.

Process Kaizen: process level and eliminating waste is the primary concern here.

Essential components of LEAN for project management (Gabriel,1997) Client:

Individual project sponsors represent stakeholders.

- For on-spot decisions, single charge point, i.e., client project manager.

- The project manager is responsible for client control.

- Team approach involving expertise team, client, and contractors.
- Contract form to have a record of all that contracted to the client.

Project Team:

- Simple steps and procedures to implement.

- Every project management activity serves the direct members.

- Target base plan and control

- Control change management without assigning authority.

Lean in process improvement deals with seven different types of waste. (MELTON)

(1) Overproduction: It happened when the operations were supposed to stop, but still, it continues. It results in unused products, products availability at an early stage, and inventory expansion.

(2) Waiting: It is the time when many downstream processes are in queue as upstream activities are not finished.

(3) Transport: Unfinished products are move from one activity to another.

(4) Extra Processing: Defects, overproduction these things leads to rework, reprocessing.

(5) Inventory: Many of the inventories are present even if it is not usable.

(6) Motion: Extra process involved to deal with defects, inventory excess.

(7) Defects: Goods or services that do not fit customer satisfaction.

\section{Conclusion}

It appears worth mentioning that although the above strategies are helpful for management and improvement of process, but still all of them has some issues. Working towards implementing those approaches can lead to further enhancement and up-gradation. Management and Improvement process are never possible without correct data and information. To increase quality of such data is the main focus which automatically will impact other future approach and techniques with minimal problem concerns.

\section{References}

[1] Anbari, F. (2002). Six sigma method and its applications in project management. Project Management Institute. Antony, J., B.R. (????). A strategy for survival.

[2] Antony, J., B.R. (2002). Key ingredients for the effective implementation. Manufacturing Engineer.

[3] Azvine, B., C. Z..N.D.D. (2005). Towards real-time business intelligence. BT Technology Journalt, 23, 214- 225. B. Azvine, D. Nauck, Z.C. (2005). Towards real-time business intelligence. BT Technology Journal, 214225.

[4] Bruckner, R. M., L.B. and Schiefer, J. (2002). Striving towards near real-time data integration for data warehouses. in: Kambayashi, y., winiwarter, w., arikawa. M. (Eds.): Proceedings of the DaWaK Berlin et al, 38, 317-326. 